\title{
THERMOGRAPHY IN THE INVESTIGATIONS OF THE THERMAL DEFORMATIONS IN NC MACHINE TOOL BODIES
}

\author{
Roman Staniek \\ Poznan University of Technology, Institute of Mechanical Technology \\ ul. Piotrowo 3, 61-138 Poznan \\ E-mail: Roman.Staniek@put.poznan.pl Tel. ++48616652758 Fax ++48616652200
}

Key words: NC machine tools, thermography, thermal deformations, compensation methods

The essence of thermal phenomena occurring in NC machine tools as well as their influlence on the thermal deformations has been described in the paper. The influence of the thermal deformations upon the NC machine tool accuracy has been also discussed. There have been pointed out sources and flow ways of the heat streams in the system of NC machine tool - environment by means of radiation, convection and conduction. There have been discussed the influence of the structure and design upon the machine tool thermal properties and on the machine tool deformations.

The paper presents the role and significance, which are contemporary played by the thermographic investigations of the thermal states and effects by means of an infrared camera (Fig. 1 and Fig. 2). There is presented their vital importance in the area of diagnostics the sources and intensity of heat, as well as the influence on the positioning accuracy.

a)

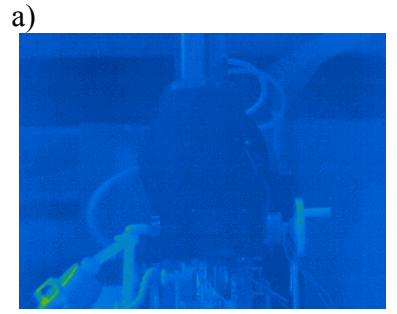

d)

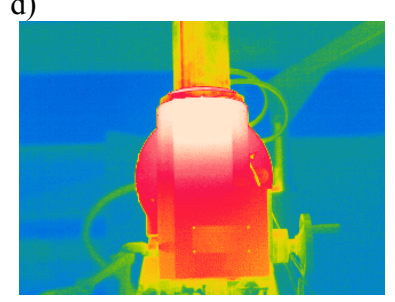

b)

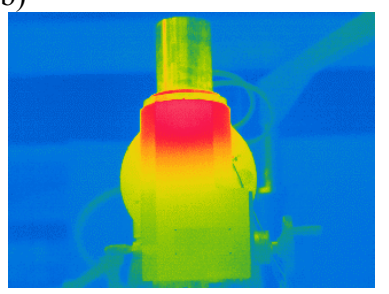

e)

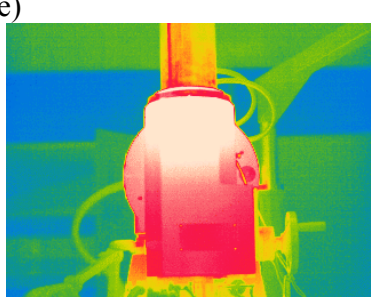

c)

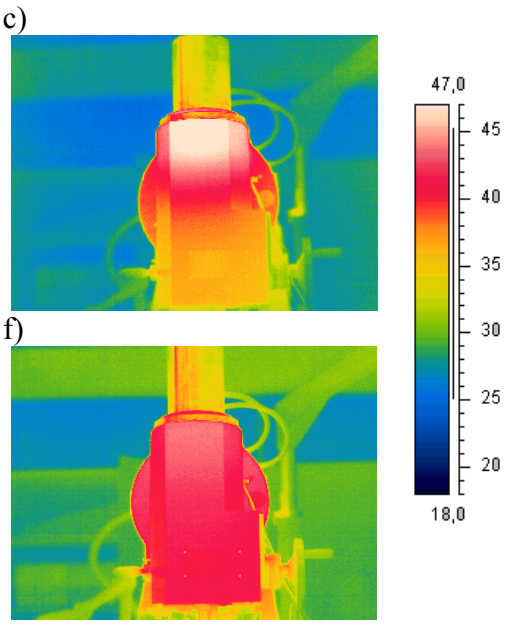

Fig.1. Thermograms of the face surface in the spindle head of the milling machine working in idle run performed after: a - 0 min, b - 60 min, c - $120 \mathrm{~min}, \mathrm{~d}-180 \mathrm{~min}$, e - $240 \mathrm{~min}$ and $\mathrm{f}$ - $300 \mathrm{~min}$ of work

a)

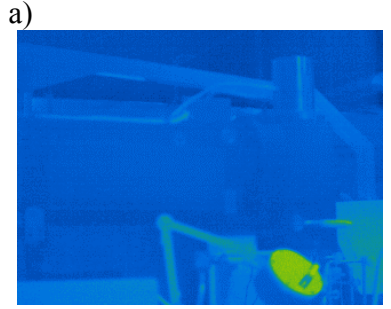

d)

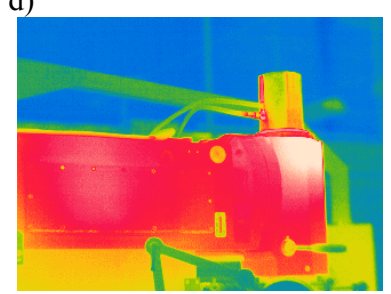

b)

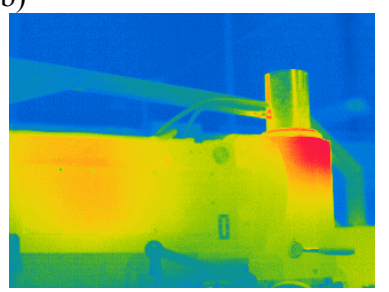

e)

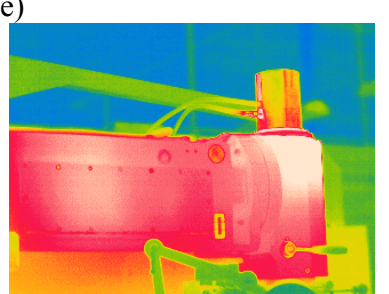

c)

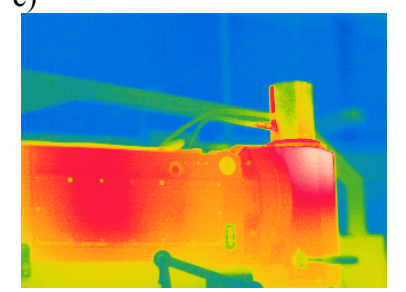

f)

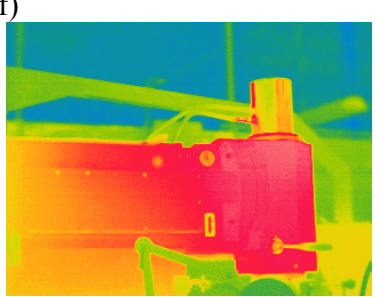

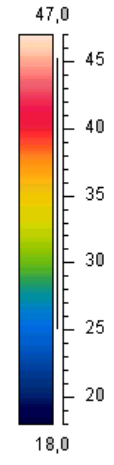

Fig. 2. Thermograms of the side surface in the beam of the milling machine working in idle run performed after: a - 0 min, b - 60 min, c - $120 \mathrm{~min}, \mathrm{~d}-180 \mathrm{~min}, \mathrm{e}-240 \mathrm{~min}$ and f - $300 \mathrm{~min}$ of work 
Describes the measuring system of thermal displacements. Experimental investigation results of the linear deformations according to the ISO 230/3 standard demanding in three axis and angular deformations in two axis of the NC milling machine have been presented (Fig. 3 and Fig. 4).

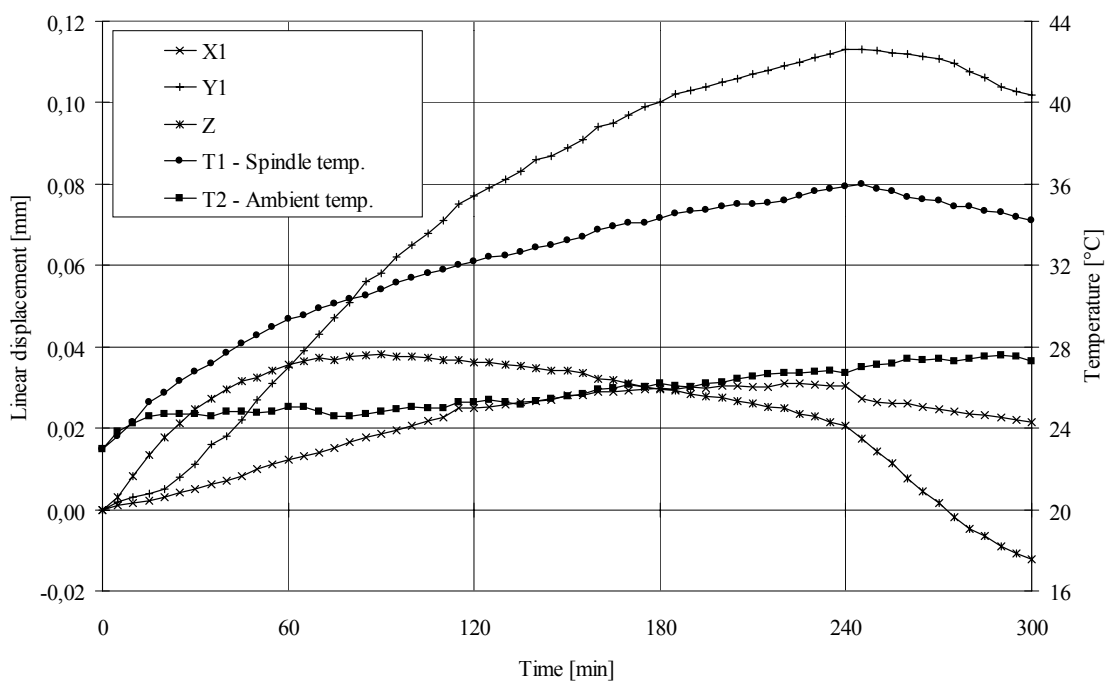

Fig. 3. Linear displacements of the spindle end in $\mathrm{X}, \mathrm{Y}, \mathrm{Z}$ axis and temperature courses (ambient and spindle) in idle run of milling machine

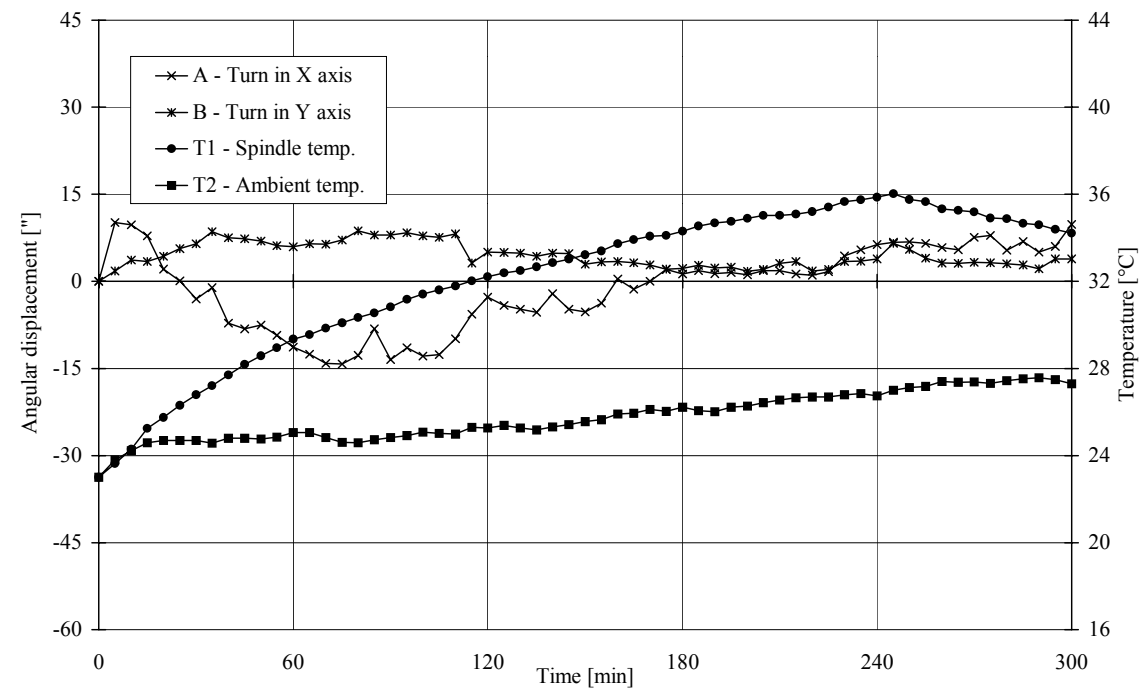

Fig. 4. Angular displacements of spindle head in $\mathrm{X}$ and $\mathrm{Y}$ axis and temperature courses (ambient and spindle) in idle run of milling machine

Describes the compensation methods of thermal deformations in machine tools connected with linear and angular displacements and their effectiveness. The effects of the compensation have been also presented. 